\title{
Engineering behaviour of stabilized laterite and kaolin using lignin
}

\author{
Tuan Noor Hasanah Tuan Ismail ${ }^{1, *}$, Siti Aimi Nadia Mohd Yusoff ${ }^{2}$, Ismail Bakar ${ }^{3}$, \\ Devapriya Chitral Wijeyesekera ${ }^{3}$, Adnan Zainorabidin ${ }^{3}$, Mastura Azmi $^{2}$, Muhd Harris \\ Ramli $^{2}$, and Alvin John Lim Meng Siang ${ }^{3}$ \\ ${ }^{1}$ Department of Civil Engineering Technology, Faculty of Engineering Technology, Universiti Tun \\ Hussein Onn Malaysia, 86400 Parit Raja, Batu Pahat, Johor, Malaysia. \\ ${ }^{2}$ School of Civil Engineering, Universiti Sains Malaysia, Engineering Campus, 14300 Nibong Tebal, \\ Seberang Perai Selatan, Pulau Pinang, Malaysia. \\ ${ }^{3}$ Faculty of Civil and Environmental Engineering, Universiti Tun Hussein Onn Malaysia, 86400, \\ Parit Raja, Batu Pahat, Johor, Malaysia.
}

\begin{abstract}
Soils at many sites do not always have enough strength to bear the structures constructed over them and some of the soil may need to be stabilized in order to improve their geotechnical properties. In this paper, routine laboratory tests were critically carried out to investigate the efficacy of lignin in improving the strength behaviour of the soils. Two different soil samples (laterite and kaolin) were studied and mixed with different proportions of lignin (2\% and 5\% of dry weight of soil), respectively. Unconfined Compressive Strength (UCS) characteristics evaluated in this study were done on samples at their maximum dry density and optimum moisture content (obtained from compaction tests). The UCS tests on all the specimens were carried out after $0,7,15,21$ and 30 days of controlled curing. The research results showed that the addition of lignin into kaolin reduced its maximum dry density while giving progressively higher optimum moisture content. Contrarily, with the laterite soil, both maximum dry density and optimum moisture content simultaneously increased when lignin was added into the soils. The UCS results showed that the the stabilized laterite with $2 \%$ lignin continued to gain strength significantly at a fairly steady rate after 7 days. Unfortunately, lignin did not show a significant effect in kaolin.
\end{abstract}

\section{Introduction}

In most tropical countries, the road network consists of paved and unpaved roads [1]. Both good paved and unpaved road require a suitable foundation, which in turn may require soil stabilization. This degree of stability is primarily a function of the road material's resistance to lateral movement or flow. Different types of road material employ different mechanisms for resisting lateral movement [2]. In general, granular soil count on their particle sizes, angularity, and interlocking ability to develop the internal friction required to resist lateral flow $[3,4]$. However, in fine-grained soils such as clay soils, the stability is very much moisture-dependent. As a result, well-established techniques of stabilization are often used 
to improve the properties of geotechnical materials through the addition of binding agents into the soil [2]. For example, in the case of some soils, poor load-bearing qualities can be improved. In the case of less permeable soils, they may be stabilized to prevent rutting, frost heaving, and other adverse phenomena associated with weakening by water [5]. Soil stabilization in geotechnical engineering refers to the process of blending and mixing materials with a soil to increase the shear strength of that soil corresponding to the given requirements [2].Soil stabilization defines as a treatment of soils to correct the natural deficiencies thereof, and to render them more suitable for use as road-building material [3]. Lignin is an industrial by-product, stockpiles of which has been implicated as having a positive role in soil stabilization. Lignin is also used in combination with other chemicals to achieve soil improvement [6]. Lignin as soil additive causes dispersion of the clay fraction of some soils, resulting in the shear strength increase of the soil [3]. The dispersion of the clay fraction benefits stability of the soil-aggregate mix by: a) plugging voids and consequently improving water tightness and reducing frost susceptibility, b) eliminating soft spots caused by local concentrations of binder soil, c) filling voids with fines thus increasing density, and d) increasing the effective surface area of the binder fraction which results in a greater contribution to strength [7]. For example, a soil which is hard and resists the abrasive and impact action of traffic can be blended with a soil which may 'provide for interlocking of the soil grains and thereby affect an increase in shear strength. Clay-like materials might be added to absorb water and maintain stability in dry weather. Silt might also be desired to act as filler and to provide a capillary bond in the presence of water when the clay becomes weak by losing cohesion in wet weather.

Various studies on lignin as a soil additive have been concluded; that lignin is primarily a binding agent [2]; Lignin has been in use as an additive to the soil for many years. In an attempt to improve the action of lignin, the chrome-lignin process was developed and studied [8]. An insoluble gel is formed when sodium bichromate or potassium bichromate is added to the sulphate waste [9]. The effect of lignin on the soil properties is based on the form of lignin and the type of soil treated. The use of lignin in soil stabilization has been studied over the past decades [10]. Adding lignin to clayey soils increases the soil stability by causing dispersion of the clay fraction [2]. Lignin based stabilizers such as ammonium persulfatelignin,sodium bichromate-lignin etc. were applied as grouts to bind particles together especially in fine granular soils [11]. Since properties of lignin based stabilizers vary significantly with extraction process, there is no standard stabilization mechanism for these stablisers conforming to the general definition assumed in traditional stabilizer such as cement, lime, etc. Different kinds of lignin stabilisers with different properties are available in the market and therefore, it is necessary to examine their effects on the related soil specimens before applying in the field [12]. This paper discusses the effect of Lignin on a laterite and manufactured kaolin soil in terms of laboratory measured compaction and strength properties (UCS). Detailed data analysis of laboratory test results in comparing treated soils with untreated soils under different moisture conditions and different percentage of lignin were presented.

\section{Experimental program}

\subsection{Materials}

Materials used in the experimental research program include laterite, kaolin and lignin (as a soil stabilizer). 


\subsubsection{Soils}

Two types of soil samples were used in this study, which were laterite and kaolin. Laterite was collected from Bukit Banang in Batu Pahat, Johor. Kaolin used in this study was a manufactured material and all of the soil passed $75 \mu \mathrm{m}$ sieve. All of the soils used in this study were disturbed samples as its degree of disturbance was not deemed to have an effect particularly in the compaction tests.

\subsubsection{Lignin}

Commercial lignin was used throughout this study as a stabilizer. This lignin having a dark brown, free-flowing liquid fuel with a smoky odour reminiscent of the plant from which it is derived. It is formed in a process called fast pyrolysis where plant material (biomass), such as forest residues (bark, sawdust, shavings, etc.) and agricultural residues (sugarcane, cornhusks, bagasse, wheat straw, etc.), are exposed to $400^{\circ} \mathrm{C}$ to $500^{\circ} \mathrm{C}$ in an oxygen-free environment [2].

\subsection{Test plan and procedures}

Classification test (particle size distribution) and index properties test (moisture content, Atterberg limits and specific gravity) of soils were determined to establish the basic characteristic of soils. These tests were carried out in accordance with British Standard (BS 1377:1990). Compaction test was conducted to determine the optimum moisture content (OMC) at which maximum dry density (MDD) was attained using a standard proctor compaction test. Further laboratory tests were done to investigate the strength behaviour of stabilized soils. It was done through unconfined compressive strength (UCS) testing with the soil samples being prepared based on the outcome of the compaction test.

The natural soil collected was dried, broken down to particle sizes that would pass a $4.75 \mathrm{~mm}$ sieve. The soil was mixed with $2 \%$ and $5 \%$ of lignin by dry weight of soil. The untreated soils were also tested without the addition of Lignin. The samples were mixed manually with proper care to obtain a homogeneous mix and then the appropriate amount of water was added corresponding to the optimum moisture content obtained from compaction testing. The blended soil samples used in the UCS test were compacted and was sealed in a plastic wrap and then placed in a box that was quarter filled with water and placed in a temperature-controlled room which was maintained at $25^{\circ} \mathrm{C}$. The treated samples for UCS tests were cured for $0,7,15,21$ and 30 days to allow reactions between the stabilizer on the soil before conducting evaluation tests. The UCS test was conducted in accordance with BS standard 1377-1990 part 7. All experiments carried out were done with three replicates.

\section{Result and discussion}

\subsection{Classification and index properties test}

Soil classification tests were performed based on the procedure as specified in Head (1986) [13] and BS1377:1990. Based on the particle size distribution curve as shown in Figure 1 for both laterite and kaolin sample, it was found that both soil were primarily fine grained. The classification properties of the test soils are summarized in Table 1, including the $\mathrm{pH}$ value and some other index properties of soil. The liquid limit (LL) and plasticity index (PI) values of $66 \%$ and $42.9 \%$ for laterite, and $74 \%$ and $30.17 \%$ for kaolin. According to the Unified Soil Classification System (USCS) both soils used in this study can be classified as being a high plasticity clay $(\mathrm{CH})$. Whereas according to the AASHTO classification system, these soils 
are classified to be in the group of A-8 and A-7-5 for laterite and kaolin, respectively. The chemical composition of lignin is as shown in Table 2.

Table 1. Summary of index properties of the studied soil.

\begin{tabular}{|c|l|c|c|c|}
\hline Basic Properties & \multicolumn{1}{|c|}{ Parameter } & Unit & Laterite & Kaolin \\
\hline \multirow{5}{*}{ Textural Composition } & Gravel & $\%$ & 6.690 & - \\
\cline { 2 - 5 } & Sand & $\%$ & 32.512 & - \\
\cline { 2 - 5 } & Silt & $\%$ & 11.796 & 87.67 \\
\cline { 2 - 5 } & Clay & $\%$ & 49.003 & 12.35 \\
\cline { 2 - 5 } & $\mathrm{D}_{10}$ & $\mathrm{~mm}$ & 0.0019 & 0.0014 \\
\cline { 2 - 5 } & $\mathrm{D}_{30}$ & $\mathrm{~mm}$ & 0.0090 & 0.0040 \\
\cline { 2 - 5 } & $\mathrm{D}_{60}$ & $\mathrm{~mm}$ & 0.2 & 0.0086 \\
\cline { 2 - 5 } & $\mathrm{Cu}$ & - & 105.26 & 6.143 \\
\cline { 2 - 5 } & $\mathrm{Cc}$ & - & 0.213 & 1.329 \\
\hline \multirow{5}{*}{ Poil Classification } & USCS & - & $\mathrm{CH}$ & $\mathrm{CH}$ \\
\cline { 2 - 5 } & AASHTO & - & $\mathrm{A}-8$ & $\mathrm{~A}-7-5$ \\
\hline & Moisture Content & $\%$ & 22.54 & 0.22 \\
\cline { 2 - 5 } & Specific gravity & - & 2.79 & 2.47 \\
\cline { 2 - 5 } & Liquid Limit & $\%$ & 66 & 74 \\
\cline { 2 - 5 } & Plastic Limit & $\%$ & 42.9 & 30.17 \\
\cline { 2 - 5 } & Plastic Index & $\%$ & 42.9 & 30.17 \\
\hline Chemical Properties & pH & & 5.95 & 5.54 \\
\hline
\end{tabular}

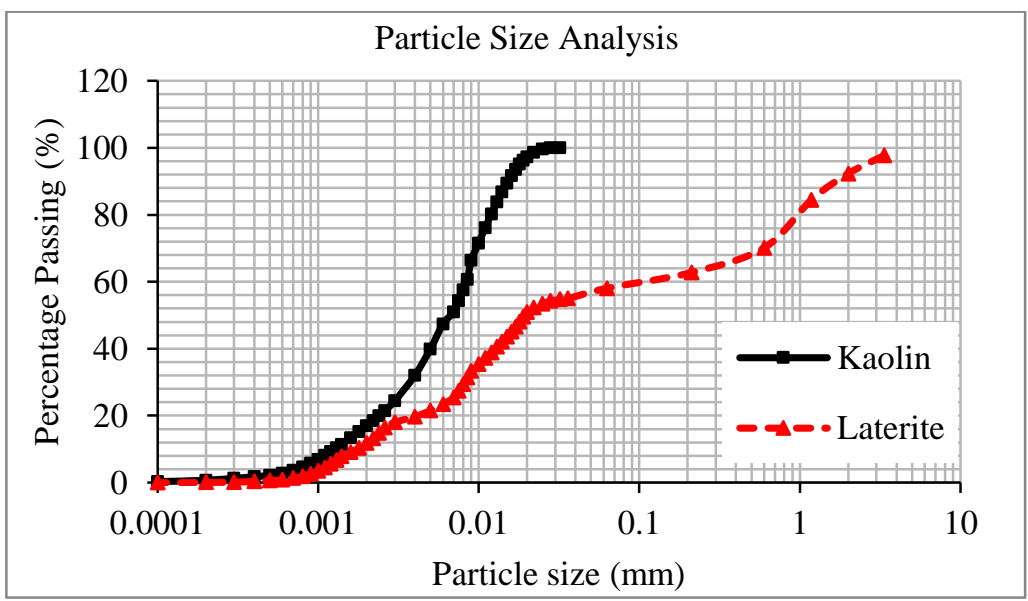

Fig. 1. Particle size distribution curve of kaolin and laterite (before stabilization).

Table 2. Chemical composition of lignin.

\begin{tabular}{|c|c|}
\hline Chemical elements & Concentration (\%) \\
\hline Calcium $(\mathrm{Ca})$ & 0.0265 \\
\hline Methylene $\left(\mathrm{CH}_{2}\right)$ & 99 \\
\hline Potassium $(\mathrm{K})$ & 0.0138 \\
\hline Manganese $(\mathrm{Mn})$ & 0.001 \\
\hline Sodium $(\mathrm{Na})$ & 0.264 \\
\hline Phosphorus $(\mathrm{P})$ & 0.0411 \\
\hline Sulfur $(\mathrm{S})$ & 0.6699 \\
\hline
\end{tabular}




\subsection{Compaction characteristics}

Both Standard and Modified proctor tests were performed on treated/untreated kaolin and laterite to determine the optimum moisture content (OMC) and maximum dry density (MDD) relationship. The results have been summarized and presented in Table 3. Figures 2 and 3 further show that the OMC and MDD pattern of two soil samples when mixed with different proportion of lignin by using standard and modified proctor apparatus, respectively.

Table 3. Summary of Standard and Modified Proctor test of treated/untreated laterite and kaolin.

\begin{tabular}{|c|c|c|c|c|c|}
\hline \multirow{3}{*}{ Soil } & \multirow{2}{*}{ \% Lignin } & \multicolumn{2}{|c|}{ Standard Proctor Test } & \multicolumn{2}{c|}{ Modified Proctor Test } \\
\cline { 3 - 6 } & $\begin{array}{c}\mathrm{MDD} \\
\left(\mathrm{Mg} / \mathrm{m}^{3}\right)\end{array}$ & $\begin{array}{c}\text { OMC } \\
(\%)\end{array}$ & $\begin{array}{c}\mathrm{MDD} \\
\left(\mathrm{Mg} / \mathrm{m}^{3}\right)\end{array}$ & $\begin{array}{c}\text { OMC } \\
(\%)\end{array}$ \\
\hline \multirow{3}{*}{ Kaolin } & Control $(0 \%)$ & 1.41 & 27 & 1.46 & 23 \\
\cline { 2 - 6 } & $2 \%$ & 1.29 & 33 & 1.51 & 21 \\
\cline { 2 - 6 } & $5 \%$ & 1.33 & 33 & 1.54 & 20 \\
\hline \multirow{3}{*}{ Laterite } & Control (0\%) & 1.60 & 23.8 & 1.77 & 16.5 \\
\cline { 2 - 6 } & $2 \%$ & 1.63 & 22.5 & 1.84 & 16 \\
\cline { 2 - 6 } & $5 \%$ & 1.66 & 20 & 1.85 & 15 \\
\hline
\end{tabular}

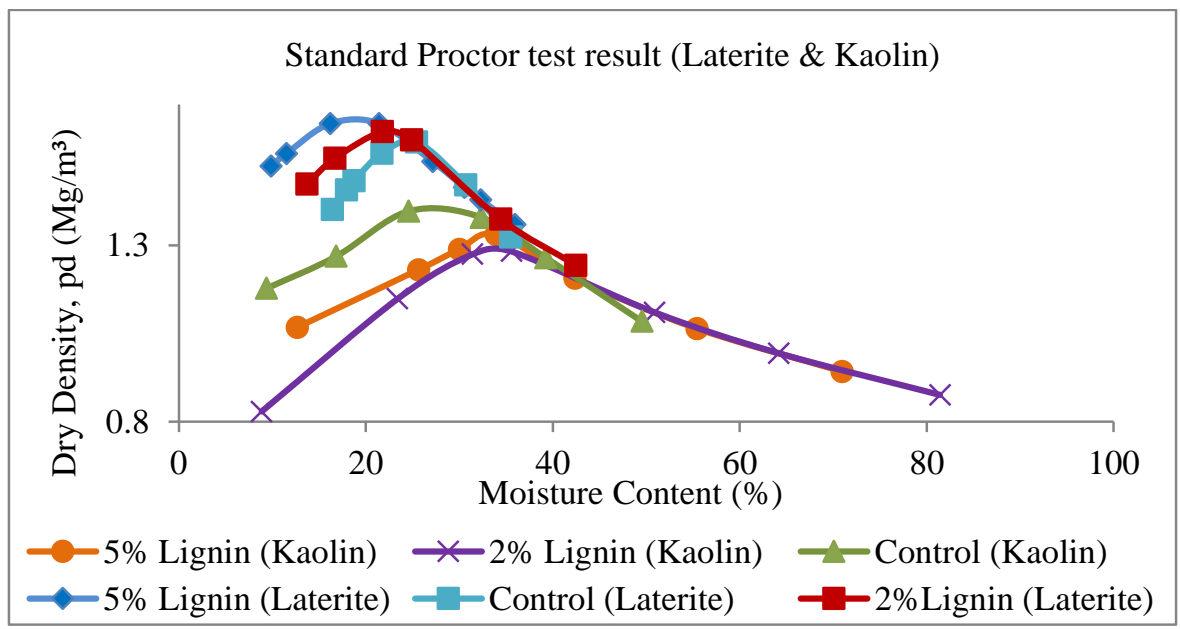

Fig. 2. Compaction characteristic curve for stabilized soil using standard proctor test.

Based on results in Figure 2 for standard compaction test, it can be seen that the MDD of kaolin decreased with the increase of the lignin percentage. This effect can be attributed to the flocculation of soil particles. It was found that the changes in compaction characteristics of treated kaolin are minimal. This is due to a high clay content, as kaolin contained $87.67 \%$ of clay fraction. According to Stan \& Ciobanu (2012) [14], the minimum clay content has to be at least $10 \%$, and the soil to be stabilized has to present a plasticity index greater than $8 \%$. The best results are obtained in soils having clay content between 12 and $24 \%$ (even 25 to $30 \%$ ) [14]. Whereas the increase in OMC value from $27 \%$ at $0 \%$ lignin to $33 \%$ at $2 \%$ to $5 \%$ lignin is probably a consequence of additional water held within the flocculated soil structure resulting from lignin reaction. Laterite sample has a MDD value of $1.60 \mathrm{Mg} / \mathrm{m}^{3}$ at $0 \%$ lignin percentage, and increased to $1.66 \mathrm{Mg} / \mathrm{m}^{3}$ at $5 \%$ lignin percentage. However, it was noticed that the $\mathrm{OMC}$ value is decreased with increase of lignin percentage from $0 \%$ to $5 \%$. 


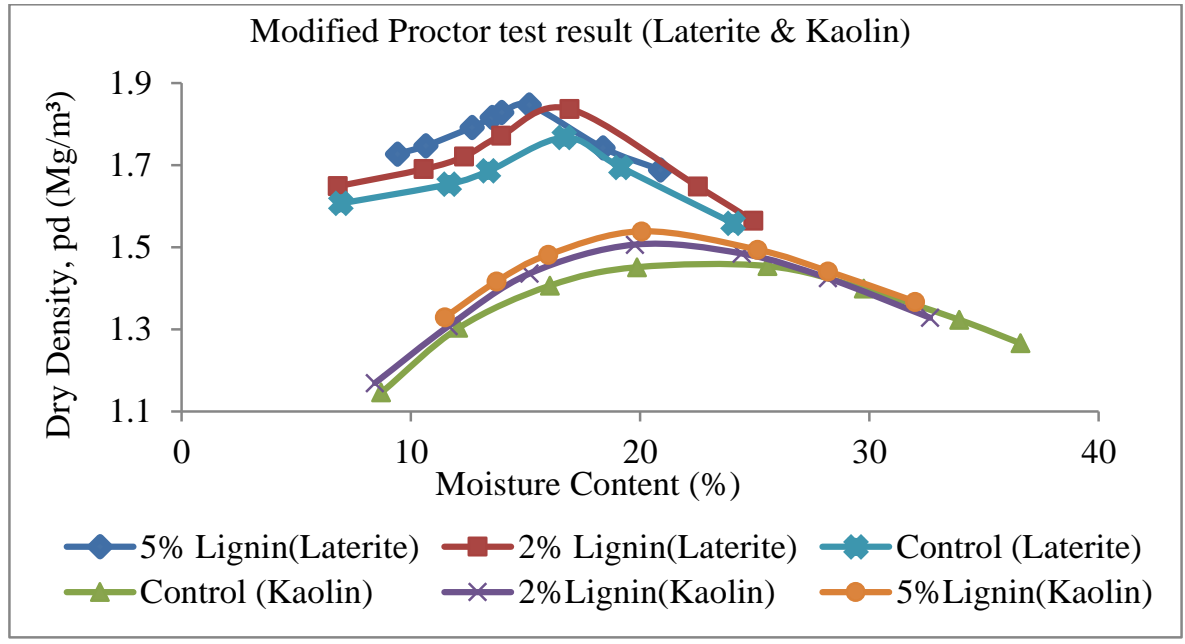

Fig. 3. Compaction characteristic curve for stabilized soil using modified proctor test.

Furthermore, Figure 3 shows the modified compaction curves for treated/ untreated kaolin and laterite. It can be seen that the both laterite and kaolin mixed with 5\% lignin gives the lowest $\mathrm{OMC}$ of $15 \%$ and $20 \%$ and highest MDD of $1.85 \mathrm{Mg} / \mathrm{m}^{3}$ and $1.54 \mathrm{Mg} / \mathrm{m}^{3}$, respectively.If compared (laterite \& Kaolin) the curve trend with standrad proctor and modified poctor test, it was found that the more amount lignin were added the higher MDD is recorded of stabilize soil. This is probably related to the fact that lignin is a dispersing agent, and when incorporated in soil it increases the effective surface area, especially that of the clay-size fraction.And this is also due to the voids within the coarse aggregates being filled with small particles under the influence of higher compactive energy. The flocculation of the solid particles implies that the water-additives-soil mixtures can be compacted with lower water content (due to the high compactive effort), and the optimum water content is reduces. Therefore, increasing the compaction effort could be an important element in improving the engineering behaviour.

\subsection{Strength characteristics}

The UCS tests were performed at $0,7,15,21$ and 30 days of curing periods. Table 4 and Figure 4 show the strength pattern of both samples when mixed with different percentage of lignin. It was observed that the strength of soil increased with increase of curing time. The result indicates that maximum strength is found in the laterite treated with $2 \%$ lignin, while treated kaolin shows small improvement in the strength. Figures 4(a) shows that the treated laterite with $2 \%$ lignin continued to gain strength after 0 days of curing.

Figures 4 (b) show that the increased lignin percentage resulted in a slight improvement in strength after 21 days of curing. This is due to the particle size of kaolin. According to [2] lignin should be much more effective as stabilizing agents for granular soil or soil aggregate mixture. It can be concluded that the addition of $2 \%$ lignin to the laterite with the suitable moisture content will cause the strength characteristic becoming more stable as compared to the soil specimens containing 5\% Lignin. 
Table 4. Summary of UCS test of treated/untreated kaolin and laterite cured to $0,7,15,21$ and 30 days.

\begin{tabular}{|c|c|c|c|c|c|c|}
\hline \multirow{3}{*}{ Days } & \multicolumn{5}{|c|}{ Unconfined Compressive Strength (kPa) } \\
\cline { 2 - 7 } & \multicolumn{3}{|c|}{ Laterite } & \multicolumn{3}{c|}{ Kaolin } \\
\cline { 2 - 7 } & control & $2 \%$ & $5 \%$ & ctrl & $2 \%$ & $5 \%$ \\
\hline 0 & 512.02 & 592.69 & 447.25 & 219.33 & 134.42 & 120.27 \\
\hline 7 & 513.93 & 640.30 & 548.41 & 229.65 & 171.82 & 180.31 \\
\hline 15 & 510.02 & 754.66 & 638.58 & 231.03 & 233.4 & 202.27 \\
\hline 21 & 515.87 & 787.42 & 750.61 & 247.23 & 241.35 & 247.23 \\
\hline 30 & 513.73 & 804.53 & 738.76 & 224.07 & 247.23 & 265.81 \\
\hline
\end{tabular}

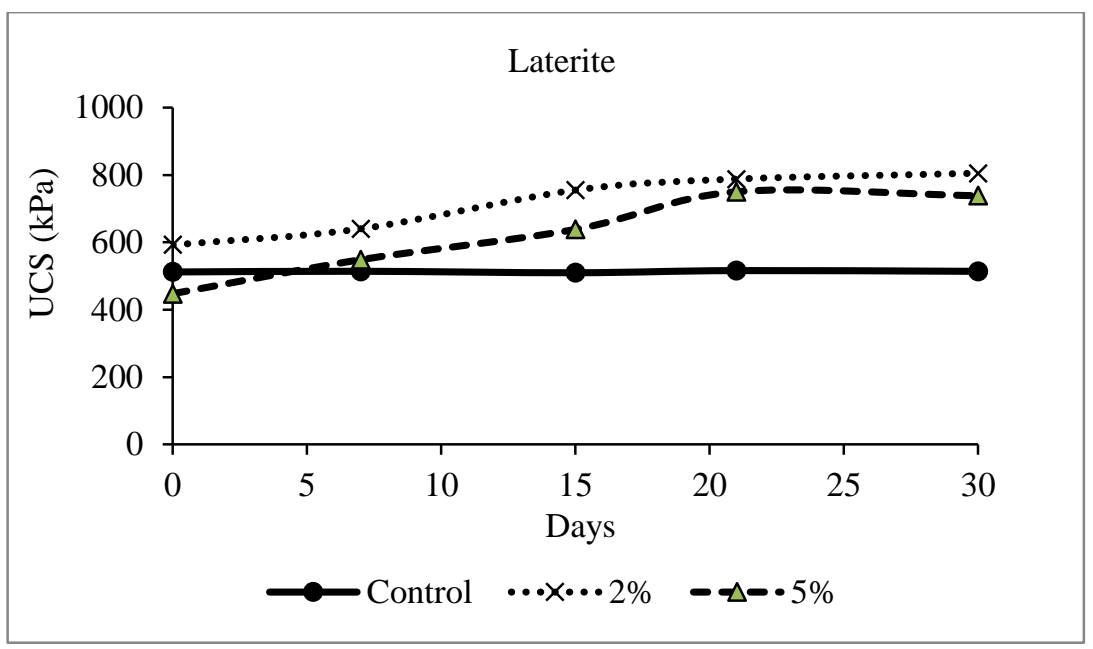

(a)

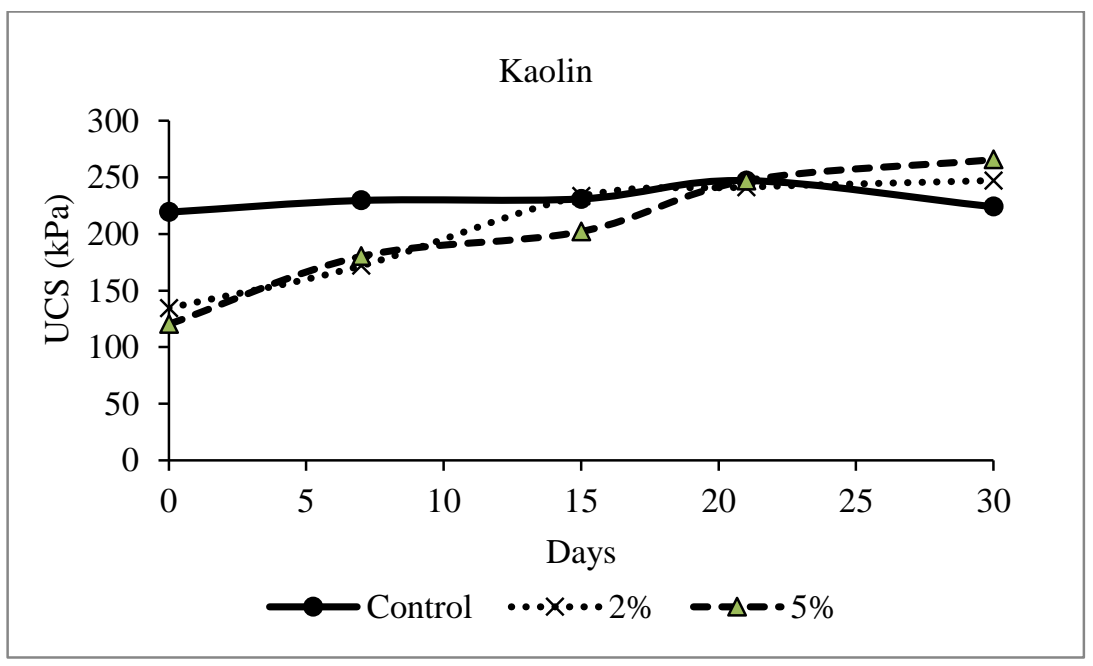

(b)

Fig. 4. Strength behavior of stabilized Laterite; (a) and stabilized Kaolin (b) with different percentage of lignin. 


\section{CONCLUSION}

The investigation was conducted to study the effect of adding Lignin on kaolin and laterite. The soil was tested for Atterberg Limit (LL and PL), moisture content, specific gravity, particle size analysis, standard and modified proctor test and unconfined compressive strength (UCS). Lignin with a suitable mixing content could be effectively used to stabilize laterite. Geotechnical properties such as unconfined compressive strength and compaction behaviours of stabilized soil markedly improved. The dry density increased and the optimum moisture content decreased, except treated kaolin using standard proctor energy. The unconfined compressive strength of the treated soil is mostly increased except treated kaolin. In a nut shell, laterite can be successfully improved after stabilization with Lignin.

\section{Acknowledgements}

The author records her sincere thanks to the technicians of the Research Centre for Soft Soil (RECESS), Geotechnical and Highway \& Transportation Laboratory, Universiti Tun Hussein Onn Malaysia (UTHM) for their assistance in the experimental work and for their constant support. Financial support from Research Management Centre (RMC) and TIER 1 Research Grant (H221) are also gratefully acknowledged.

\section{References}

1. B.B.K. Huat, S.S Gue and F. Ali, Tropical Residual Soils Engineering (CRC Press, 2004)

2. H. Ceylan, S. Kim, and G. Gopalakrishnan, Sustainable Utilization of Bio-fuel CoProduct in Roadbed Stabilization. Sustainable Bioenergy and Bioproducts, 116-130 (2012).

3. J. Q. Addo, T. G. Sanders, and M. Chenard, Road Dust Suppression: Effect on Maintenance Stability, Safety and the Environment Phases 1-3. Mountain-Plains Consortium (MPC) Report No. 04-156. Fargo: 259-260 (2004).

4. A.J.M.S. Lim, D.C. Wijeyesekera, and A. Zainorabidin, The Effect of Particle Morhpology of Sand on the Realtionship between Shear Strength and Dilantancy Characteristics. Electronic Journal of Geotechnical Engineering, 18, pp 1537 - 1546 (2013).

5. A. B. Miller, Stabilization of soils, U.S. Patent No. 2375,019. Washington, DC: U.S. Patent and Trademark Office: 1-3 (1945).

6. S. Kim, K. Gopalakrishnan and H. Ceylan, Moisture susceptibility of subgrade soils stabilized by lignin-based renewable energy coproduct. J. Transp. Eng. 138 (11), 1283 1290 (2011).

7. A. J. Gow, D. T. Davidson, and J. B. Sheeler, Relative effects of chlorides, lignosulfonates and molasses on properties of a soil-aggregate mix. (Highway Research Board Board Bulletin: 282, 1961).

8. C. Venkatramaiah, Geotechnical Engineering : Revised Third Edition. New Age International Publishers: 707-708 (2006).

9. P. P. Raj, Ground Improvement Techniques. (Laxmi Publications pp. 191, 2005). 
10. B. Indraratna, T. Muttuvel, H. Khabbaz, \& R. Armstrong, Predicting the erosion rate of chemically treated soil using process simulation apparatus for internal crack erosion. Journal of Geotechnical and Geoenvironmental Engineering, 134(6), pp. 837-844 (2008).

11. K. Gopalakrishnan, S. Kim and H. Ceylan, Lignin utilization and recovery. In: Khanal (ed) Biofuel and Bioenergy from Biowastes and Lignocellulosic Biomass.American Society of Civil Engineers (ASCE) Press.Reston,VA: 120-123 (2010).

12. B. Indraratna, R. Athukorala and J. Vinod, Estimating the rate of erosion of a silty sand treated with lignosulfonate. Journal of Geotechnical and Geoenvironmental Engineering, 139, no.5,pp. 701-714 (2013).

13. K. H. Head, Manual of soil laboratory testing. 1, (John Wiley \& Sons, New York, N.Y., 1986)

14. C. Stan, \& V. Ciobanu, Using Enzymatic Emulsions to Reinforced Road Layers.

Bulletin of the Transilvania University of Brasov, Series II. Forestry, Wood Industry, Agricultural Food Engineering, 1 (2012). 